\title{
Can environmental factors increase the risk of multiple sclerosis? A narrative review
}

\author{
Hoda Naghshineh ${ }^{1,2}$, Seyed Mohammad Masood Hojjati ${ }^{1,2, *}$, Ali Alizadeh Khatir ${ }^{1,2}$, Payam Saadat ${ }^{1,2}$, \\ Alijan Ahmadi Ahangar ${ }^{1,2}$
}

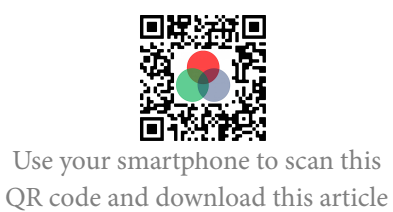

${ }^{l}$ Mobility Impairment Research Center, Health Research Institute, Babol University of Medical Sciences, Babol, Iran

${ }^{2}$ Department of Neurology, Babol University of Medical Sciences, Babol, Iran

\section{Correspondence}

Seyed Mohammad Masood Hojjati, Mobility Impairment Research Center, Health Research Institute, Babol University of Medical Sciences, Babol, Iran

Department of Neurology, Babol University of Medical Sciences, Babol, Iran

Email: hojjatiseyedmohammadmasood@gmail.com

\section{History}

- Received: Aug 25, 2019

- Accepted: Nov 10, 2019

- Published: Dec 02, 2019

DOI : 10.15419/bmrat.v6i12.579

\section{Check for updates}

\section{Copyright}

(C) Biomedpress. This is an openaccess article distributed under the terms of the Creative Commons Attribution 4.0 International license.

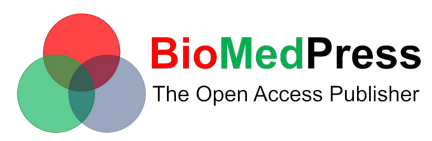

\begin{abstract}
Multiple sclerosis (MS) is one of the most common neurological disorders, which causes nontrauma in young adults in many countries. An important symptom of a disease is the presence of plaque in the brain or the spinal cord, which includes a demyelination region along with relative preservation of axons that may vary in acute and chronic stages. This review was conducted using related keywords through searching in scientific databases. Assessing the related papers showed that in general, MS is recognized as an autoimmune disease with genetic background caused by uncertain environmental factors. Epidemiological effects based on race, sex, geographical location are strongly linked to the frequency, types and severity of the disease. Vitamin D, infection, smoking and diet have been reported to be potential factors associated with MS. Due to the importance of these factors in MS disease, the control of them is potentially useful to prevent the disease and the rapid progression and exacerbation of its symptoms.

Key words: Multiple sclerosis, risk factors, review
\end{abstract}

\section{INTRODUCTION}

Multiple sclerosis (MS) is one of the most common neurological disorders and is one of the causes of nontrauma in young adults in many countries ${ }^{1}$. It is a chronic and progressive disease of the central nervous system, which can infrequently affect the peripheral nerves and may lead to associated symptoms and complications ${ }^{2,3}$. The pathogenesis of this disease is not fully understood. The activation of immune mechanisms against myelin antigen appears to be involved in the development of the disease, which can be due to genetic, environmental and immunological factors ${ }^{4-6}$. Usually, the first manifestations of the disease appear in patients aged 20 to 40 years old with symptoms such as anxiety, weakness, imbalance, visual impairment, and mental changes such as depression, disappointment, and reduced ability to resolve problems ${ }^{7-9}$. There are more than 400,000 people in North America, around 500,000 people in Europe, and 2.5 million people worldwide affected by the disease ${ }^{10}$.

MS is seen in both recurrent and progressive forms (primary or secondary) and is divided into primary and secondary progression based on the course of the disease and the occurrence of symptoms in the form of an attack-recovering type with a prevalence of about $70 \%^{11,12}$. An important symptom of the disease is the presence of plaque in the brain or the spinal cord, which includes a demyelination region along with the relative preservation of axons that vary in acute and chronic stages ${ }^{13}$. Despite the advances in medical science in recent years, there is currently no definitive and eradicating treatment for MS. Most of the existing treatments reduce the symptoms or slow the progression of disease. Therefore, rapid detection and diagnosis of disease and control during this time, can prevent severe complications and uncontrollable progress ${ }^{14}$. Considering the migration pattern of people around the world, one of the notable features of the global distribution of MS is that, with increasing latitude in the north and south of the equator, the probability of occurrence of the MS also increases several times, which indicates not only genetic factors play an important role but environmental factors can also affect the disease ${ }^{15,16}$. The present review was conducted to evaluate recent evidence on the potential environmental risk factors involved in the incidence of MS.

\section{SEARCH STRATEGY AND RESULTS}

This review was conducted using the keywords of "multiple sclerosis," "factors", and "risk factors" through searching in the scientific databases of PubMed, Scopus, and Web of Science, focusing on articles published over the recent years. Unrelated sources and articles were removed. Assessing the related papers showed that in general, MS is recognized 
as an autoimmune disease in the background of genetic factors caused by uncertain environmental factors. Epidemiological effects based on race, gender and geographical location are strongly linked to the frequency, characteristics, severity and progression of the disease ${ }^{17}$. Different environmental factors play a role in the pathogenesis and progression of MS. Some of the most important ones are discussed in the following.

\section{VITAMIN D}

Vitamin D is a hormone that is made up of two forms of D2 and D3 (D3 forms with sunlight in the skin) ${ }^{1}$. Recent epidemiological studies have shown that the association between low vitamin D levels and increased probability of MS is likely to be due to the anti-inflammatory effects of vitamin $\mathrm{D}$ and its potential effects on cytokine levels ${ }^{18,19}$. Many studies show the effect of vitamin D on growth and maturation of immune cells such as macrophages, dendritic cells, $\mathrm{T}$ cells and B cells ${ }^{20}$. Since sun exposure induces vitamin D3 synthesis from the skin ${ }^{21}$, it is assumed that exposure to the sun in early childhood is associated with a reduction in the risk of $\mathrm{MS}^{19}$. Studies have indicated that vitamin $\mathrm{D}$ is also essential in improving regulatory function for autoimmune disease con$\operatorname{trol}^{22,23}$.

\section{INFECTION}

Although the most important factor in the occurrence of MS is genetics, environmental factors play an important role in the development of the disease as well as its recurrence. Among the environmental factors, infectious agents can also have a potential for pathogenesis ${ }^{24}$. There are different assumptions about which infectious agents, and how they are involved in the process of occurrence and progression of the disease. In studies that were carried out, different microorganisms involving in the incidence and development of MS include Human Type6 herpesvirus, Human Type-4 herpesvirus, Chlamydia pneumonia, torque teno virus, and Epstein-Barr viruses $(\mathrm{EBV})^{23,25}$. Meanwhile, EBV is important in the development of this disease. EBV is a double strain DNA virus of the family of herpes viruses, and $90 \%$ of the general population in the first decade of life is likely to be infected. The virus remains in memory cells permanently ${ }^{26}$, and can cause infectious mononucleosis in case of severe contamination. Although the mechanism for the participation of other infections in the incidence of MS is still unclear, in the case of EBV, it is believed that the exposure to the infection may increase the risk of $\mathrm{MS}^{14}$.
Various hypotheses about the function mechanism of this virus have been proposed, including the excessive activation of $\mathrm{B}$ and $\mathrm{T}$ lymphocytes during infectious mononucleosis, stimulation of B lymphocytes, cross-reactivity of viral antigens with myelin antigens, etc. Besides, EBV-infected cells in the white and gray matter of MS patients may induce $\mathrm{T}$ cell lymphocyte responses that ultimately damage the surrounding tissues ${ }^{26}$. Research has shown that the risk of MS in people with infectious mononucleosis is 2-3 times higher ${ }^{27}$. It has also been stated that the prevalence of MS patients not infected with EBV is less than $0.01 \%^{28}$.

Accordingly, although this virus is not the main cause of MS, it is necessary to develop disease progression. Recent studies have shown that antibodies against bacterial antigens, such as Acinetobacter and Pseudomonas aeruginosa, is significantly increased in $\mathrm{MS}^{29}$. These bacterial antigens are likely to interact with the myelin peptides ${ }^{30}$, causing the immune system to attack and demyelinate nerve cells.

\section{SMOKING}

Although many studies point to the role of cigarette smoking in the incidence of MS, there is still insufficient evidence for its definite role in the incidence of $\mathrm{MS}^{29}$. Smoking may be responsible for the recurrence of MS. A study conducted on American women showed that the incidence of MS in smokers is $60 \%$ higher than non-smokers and increases the likelihood of its occurrence in people who are exposed to smoke ${ }^{30}$. Cigarette compounds, such as nicotine and tobacco, cause this problem in the immune system. Researchers have shown that nicotine increases blood flow in the cerebral capillaries and increases the penetration of the solution into the blood brain barrier, and ultimate leakage from the blood brain barrier is suggested to be a factor in the development of $\mathrm{MS}^{31,32}$. Another possibility is that some compounds in cigarettes may have direct toxic effects on the central nervous system and cause myelin loss of neurons $^{33}$. Studies have shown that antibodies against chlamydia pneumoniae are more common in smokers than non-smokers ${ }^{34}$. Therefore, cigarette smoking is considered as a factor in increasing the duration and severity of respiratory infections, which may lead to infection-induced $\mathrm{MS}^{35}$. Literature has shown that smoking can decrease the activity of indole amine 2,3-dioxygenase, increase the activity of the reninangiotensin system and the levels of some of the cytokines, which can accelerate the course of MS disease and exacerbate its symptoms ${ }^{36}$. Based on studies that have been conducted to study the effect of smoking on 
the risk of incidence and developing MS, there was no relationship between the risk of MS and early stages of smoking, however, 10 years after the cessation of smoking, the risk decreases ${ }^{37}$.

\section{DIET}

Other environmental factors that can increase the risk of MS include personal diets, which can directly or indirectly affect cellular elements ${ }^{26}$. Several studies have been done to show that a diet based on high fat, cholesterol, sugars, and salt can exacerbate or increase the incidence of $\mathrm{MS}^{38}$. It is the fact that excessive fat intake causes obesity and increases the body mass index. It has been reported that there is a direct correlation between the body mass index and the risk of MS, specially in young ages ${ }^{39}$. Sodium intake is also associated with obesity and changes in body fat compositions, which plays a role in the incidence of $\mathrm{MS}^{40}$. However, unlike exposure to sunlight, vitamin D and infection, diet is not important due to the lack of evidence, but is important for the progression of the disease $^{29}$.

\section{DISCUSSION AND CONCLUSION}

MS is a central nervous system disease that affects many people in the world, especially young women, with the mechanism of myelin loss in different parts of the nervous system. Yet, the underlying cause of MS is not clear ${ }^{3}$. Genetic and environmental factors are likely to contribute to the disease. A study of MS in Canada showed that the incidence of MS in women was significantly higher than men, which probably depends on the rate of change in the environment and the interaction of the gene with the environment ${ }^{41}$. This difference is reported to be 3 to 1 in some studies, which indicates the role of environmental factors, hormonal differences, and in particular, the different geographical conditions and environments in the incidence of $\mathrm{MS}^{42}$.

In this paper, we outline the risk factors for MS pathogenesis, such as vitamin $\mathrm{D}$, exposure to sunlight, infection, cigarette, diet, and possible mechanisms for the emergence of MS. In different studies, while introducing cigarettes as a factor in preventing $\mathrm{MS}^{43}$, smoking has been identified as a factor in the accelerated process of MS and its symptoms ${ }^{36}$. We have mentioned the impact of infection on MS with various bacterial and viral pathogens, especially the EBV virus, which can be essential to contribute to the pathogenesis of this disease ${ }^{23,25,29}$. It is worth noting that some studies also referred to the effects of parasites on the onset of the disease and its impact on the process ${ }^{16}$. Other infectious agents, as an environmental factor, can be associated with fungal infections. HLA-DRB1 allele, which is the most important genetic risk factor for MS, is associated with fungal infections. Many cytokines and markers involved in fungal infection such as interleukin 17, chitotriosidase and antibodies against fungus are also involved in MS disease and can be pathogenic ${ }^{44}$. In relation to the diet, the conducted experiments prevented people with MS from a high-fat diet, high in cholesterol, sugar, and sodium, to prevent the exacerbation of disease symptoms ${ }^{38}$. Therefore, due to the importance of these factors in MS disease, the control of them by prevention and/or care is potentially useful to prevent the disease, and also because of the progression of MS, these measures to prevent the rapid progression of the disease and exacerbate its symptoms are essential.

Due to the progression of MS, today, there are many different treatments for MS patients that can prevent the exacerbation of the symptoms and progression. The primary goal of MS treatment is to reduce the rate of relapse and reduce the progression of the disease. Many studies on the natural history of MS have shown that MS can occur in two stages. The first stage is associated with a relative inflammation, which varies from time to time and until the benign disease disability it will take. The second stage and phase of the disease last for several years until the disease progresses in a uniform period. Research has shown that the first phase of the disease is likely to be better suited to start treatment and is best effective ${ }^{45}$.

Since B lymphocytes play an essential role in the pathogenesis of MS, the first line of treatment for MS disease is the use of ocrelizumab, which unlike the old drugs targeting $\mathrm{T}$ cells, targets significant cause of the pathogenesis of the disease that attacks and destroys $\mathrm{CD} 20^{+}$B lymphocytes ${ }^{46}$. Ocrelizumab is superior to interferon beta in preventing recurrence of the disease, which is used in the treatment of advanced primary $\mathrm{MS}^{46,47}$.

\section{ABBREVIATIONS}

EBV: Epstein-Barr virus

MS: Multiple sclerosis

\section{COMPETING INTERESTS}

The authors declare that they have no conflicts of interest.

\section{AUTHORS' CONTRIBUTIONS}

SMMH contributed in study design. HN and SMMH searched and summarized the data. SMMH, AAK, 
PS and AAA reviewed and edited the first draft. All authors reviewed, commented and approved the final draft.

\section{REFERENCES}

1. Brownlee WJ, Hardy TA, Fazekas F, Miller DH. Diagnosis of multiple sclerosis: progress and challenges. Lancet. 2017;389(10076):1336-46. PMID: 27889190. Available from: 10.1016/S0140-6736(16)30959-X.

2. Hojati S, Zarghami A, Yousefzad T, Hojati S, Baes M. Epidemiological Features of 263 Patients with Multiple Sclerosis Residing in Babol, Iran. J Babol Univ Med Sci. 2016;18(1):52-6.

3. Patsopoulos N, Baranzini SE, Santaniello A, Shoostari P, Cotsapas C, Wong G. The Multiple Sclerosis Genomic Map: role of peripheral immune cells and resident microglia in susceptibility. bioRxiv. 2017;p. 143933.

4. Milo R, Kahana E. Multiple sclerosis: geoepidemiology, genetics and the environment. Autoimmun Rev. 2010;9(5):387-94. PMID: 19932200. Available from: 10.1016/j.autrev.2009.11.010.

5. Lemus $H N$, Warrington $A E$, Rodriguez M. Multiple sclerosis: mechanisms of disease and strategies for myelin and axonal repair. Neurol Clin. 2018;36(1):1-11. PMID: 29157392. Available from: 10.1016/j.ncl.2017.08.002.

6. Hojjati SM, Zarghami A, Hojjati SA, Baes M. Optic neuritis, the most common initial presenting manifestation of multiple sclerosis in northern Iran. Caspian J Intern Med. 2015;6(3):151-5. PMID: 26644882.

7. Colasanti A, Guo Q, Giannetti P, Wall MB, Newbould RD, Bishop $C$, et al. Hippocampal neuroinflammation, functional connectivity, and depressive symptoms in multiple sclerosis. Biol Psychiatry. 2016;80(1):62-72. PMID: 26809249. Available from: 10.1016/j.biopsych.2015.11.022.

8. van Munster CE, Jonkman LE, Weinstein HC, Uitdehaag BM, Geurts JJ. Gray matter damage in multiple sclerosis: impact on clinical symptoms. Neuroscience. 2015;303:446-61. PMID: 26164500. Available from: 10.1016/j.neuroscience.2015. 07.006.

9. Hojjati SM, Hojjati SA, Baes M, Bijani A. Relation between EDSS and monosymptomatic or polysymptomatic onset in clinical manifestations of multiple sclerosis in Babol, northern Iran. Caspian J Intern Med. 2014;5(1):5-8. PMID: 24490005.

10. Leray E, Moreau T, Fromont A, Edan G. Epidemiology of multiple sclerosis. Rev Neurol (Paris). 2016;172(1):3-13. PMID: 26718593. Available from: 10.1016/j.neurol.2015.10.006.

11. Ghasemi N, Razavi S, Nikzad E. Multiple Sclerosis: Pathogenesis, Symptoms, Diagnoses and Cell-Based Therapy. Cell J. 2017;19(1):1-10. PMID: 28367411.

12. Dutta R, Trapp BD. Relapsing and progressive forms of multiple sclerosis: insights from pathology. Curr Opin Neurol. 2014;27(3):271-8. PMID: 24722325. Available from: 10.1097/ WCO.0000000000000094.

13. Filippi M, Rocca MA, Ciccarelli O, Stefano ND, Evangelou N, Kappos $L$, et al. MRI criteria for the diagnosis of multiple sclerosis: MAGNIMS consensus guidelines. Lancet Neurol. 2016;15(3):292-303. PMID: 26822746. Available from: 10. 1016/S1474-4422(15)00393-2.

14. Garg N, Smith TW. An update on immunopathogenesis, diagnosis, and treatment of multiple sclerosis. Brain Behav. 2015;5(9):e00362. PMID: 26445701. Available from: 10.1002/ brb3.362.

15. Munger KL, Levin LI, Hollis BW, Howard NS, Ascherio A. Serum 25-hydroxyvitamin $D$ levels and risk of multiple sclerosis JAMA. 2006;296(23):2832-8. PMID: 17179460. Available from: 10.1001/jama.296.23.2832.

16. Correale J, Gaitán MI. Multiple sclerosis and environmental factors: the role of vitamin D, parasites, and Epstein-Barr virus infection. Acta Neurol Scand. 2015;132(199):46-55. PMID: 26046559. Available from: 10.1111/ane.12431.

17. Kurtzke JF. Epidemiology and etiology of multiple sclerosis. Phys Med Rehabil Clin N Am. 2005;16(2):327-49. PMID: 15893675. Available from: 10.1016/j.pmr.2005.01.013.
18. Ascherio A, Munger KL. Epidemiology of multiple sclerosis: from risk factors to preventionupdate. Semin Neurol. 2016;36(2):103-14. PMID: 27116717. Available from: 10.1055/ s-0036-1579693.

19. Kulie T, Groff A, Redmer J, Hounshell J, Schrager S. Vitamin D: an evidence-based review. J Am Board Fam Med. 2009;22(6):698-706. PMID: 19897699. Available from: 10. 3122/jabfm.2009.06.090037.

20. Szodoray P, Nakken B, Gaal J, Jonsson R, Szegedi A, Zold E, et al. The complex role of vitamin $D$ in autoimmune diseases. Scand J Immunol. 2008;68(3):261-9. PMID: 18510590. Available from: 10.1111/j.1365-3083.2008.02127.x.

21. Hayes CE. Vitamin D: a natural inhibitor of multiple sclerosis. Proc Nutr Soc. 2000;59(4):531-5. PMID: 11115787. Available from: $10.1017 / \mathrm{S} 0029665100000768$.

22. Kang SW, Kim SH, Lee N, Lee WW, Hwang KA, Shin MS, et al. 1,25-Dihyroxyvitamin D3 promotes FOXP3 expression via binding to vitamin $D$ response elements in its conserved noncoding sequence region. J Immunol. 2012;188(11):527682. PMID: 22529297. Available from: 10.4049/jimmunol. 1101211.

23. Grytten N, Aarseth JH, Lunde HM, Myhr KM. A 60-year followup of the incidence and prevalence of multiple sclerosis in Hordaland County, Western Norway. J Neurol Neurosurg Psychiatry. 2016;87(1):100-5. PMID: 25714916.

24. Belbasis L, Bellou V, Evangelou E, loannidis JP, Tzoulaki I. Environmental risk factors and multiple sclerosis: an umbrella review of systematic reviews and meta-analyses. Lancet Neurol. 2015;14(3):263-73. PMID: 25662901. Available from: 10.1016/S1474-4422(14)70267-4.

25. Sibley WA, Bamford CR, Clark K. Clinical viral infections and multiple sclerosis. Lancet. 1985;1(8441):1313-5. PMID: 2860501. Available from: 10.1016/S0140-6736(85)92801-6.

26. Correale J, Farez MF, Gaitán MI. Environmental factors influencing multiple sclerosis in Latin America. Mult Scler J Exp Transl Clin. 2017;3(2):2055217317715049. PMID: 28638627. Available from: 10.1177/2055217317715049.

27. Thacker EL, Mirzaei F, Ascherio A. Infectious mononucleosis and risk for multiple sclerosis: a meta-analysis. Ann Neurol. 2006;59(3):499-503. PMID: 16502434. Available from: 10.1002/ana.20820.

28. Dobson R, Kuhle J, Middeldorp J, Giovannoni G. Epstein-Barrnegative MS: a true phenomenon? Neurol Neuroimmunol Neuroinflamm. 2017;4(2):e318. PMID: 28203615. Available from: 10.1212/NXI.0000000000000318.

29. Hughes LE, Smith PA, Bonell S, Natt RS, Wilson C, Rashid T, et al. Cross-reactivity between related sequences found in Acinetobacter sp., Pseudomonas aeruginosa, myelin basic protein and myelin oligodendrocyte glycoprotein in multiple sclerosis. J Neuroimmunol. 2003;144(1-2):105-15. PMID: 14597104. Available from: 10.1016/S0165-5728(03)00274-1.

30. Hernán MA, Olek MJ, Ascherio A. Cigarette smoking and incidence of multiple sclerosis. Am J Epidemiol. 2001;154(1):6974. PMID: 11427406. Available from: 10.1093/aje/154.1.69.

31. Olsson T, Barcellos LF, Alfredsson L. Interactions between genetic, lifestyle and environmental risk factors for multiple sclerosis. Nat Rev Neurol. 2017;13(1):25-36. PMID: 27934854. Available from: 10.1038/nrneurol.2016.187.

32. Weston M, Constantinescu CS. What role does tobacco smoking play in multiple sclerosis disability and mortality? A review of the evidence. Neurodegener Dis Manag. 2015;5(1):19-25. PMID: 25711451. Available from: 10.2217/nmt.14.45.

33. Marabita F, Almgren M, Sjöholm LK, Kular L, Liu Y, James $T$, et al. Smoking induces DNA methylation changes in Multiple Sclerosis patients with exposure-response relationship. Sci Rep. 2017;7(1):14589. PMID: 29109506. Available from: 10.1038/s41598-017-14788-w.

34. Kumar S, Smith-Norowitz TA, Kohlhoff $S$, Apfalter $P_{\text {, Roblin }} P_{,}$ Kutlin $A$, et al. Exposure to cigarette smoke and Chlamydia pneumoniae infection in mice: Effect on infectious burden, systemic dissemination and cytokine responses: A pilot study. 
J Immunotoxicol. 2016;13(1):77-83. PMID: 25640695. Available from: 10.3109/1547691X.2015.1006346.

35. Ramanujam R, Hedström AK, Manouchehrinia A, Alfredsson L, Olsson T, Bottai M, et al. Effect of smoking cessation on multiple sclerosis prognosis. JAMA Neurol. 2015;72(10):1117-23. PMID: 26348720. Available from: 10.1001/jamaneurol.2015. 1788.

36. Correale J, Farez MF. Smoking worsens multiple sclerosis prognosis: two different pathways are involved. J Neuroimmunol. 2015;281:23-34. PMID: 25867464. Available from: 10.1016/j.jneuroim.2015.03.006.

37. Hedström AK, Hillert J, Olsson T, Alfredsson L. Smoking and multiple sclerosis susceptibility. Eur J Epidemiol. 2013;28(11):867-74. PMID: 24146047. Available from: 10 1007/s10654-013-9853-4.

38. Riccio $P$, Rossano R. Nutrition facts in multiple sclerosis. ASN Neuro. 2015;7(1):1759091414568185. PMID: 25694551. Available from: 10.1177/1759091414568185.

39. Hedström AK, Olsson T, Alfredsson L. High body mass index before age 20 is associated with increased risk for multiple sclerosis in both men and women. Mult Scler. 2012;18(9):1334-6. PMID: 22328681. Available from: 10.1177/ 1352458512436596.

40. Farez MF, Fiol MP, Gaitán MI, Quintana FJ, Correale J. Sodium intake is associated with increased disease activity in multiple sclerosis. J Neurol Neurosurg Psychiatry. 2015;86(1):26-31. PMID: 25168393. Available from: 10.1136/jnnp-2014-307928.

41. Orton SM, Ramagopalan SV, Brocklebank D, Herrera BM, Dyment DA, Yee IM, et al. Effect of immigration on multi- ple sclerosis sex ratio in Canada: the Canadian Collaborative Study. J Neurol Neurosurg Psychiatry. 2010;81(1):31-6. PMID 19710047. Available from: 10.1136/jnnp.2008.162784.

42. Mielcarz DW, Kasper LH. The gut microbiome in multiple sclerosis. Curr Treat Options Neurol. 2015;17(4):344. PMID: 25843302. Available from: 10.1007/s11940-015-0344-7.

43. Hedström AK, Olsson T, Alfredsson L. Smoking is a major preventable risk factor for multiple sclerosis. Mult Scler. 2016;22(8):1021-6. PMID: 26459151. Available from: 10.1177/ 1352458515609794.

44. Benito-León J, Laurence $M$. The role of fungi in the etiology of multiple sclerosis. Front Neurol. 2017;8:535. PMID: 29085329. Available from: 10.3389/fneur.2017.00535.

45. Stangel M, Penner IK, Kallmann BA, Lukas C, Kieseier BC. Towards the implementation of 'no evidence of disease activity' in multiple sclerosis treatment: the multiple sclerosis decision model. Ther Adv Neurol Disorder. 2015;8(1):3-13. PMID: 25584069. Available from: 10.1177/1756285614560733.

46. Hauser SL, Bar-Or A, Comi G, Giovannoni G, Hartung HP, Hemmer $B$, et al. Ocrelizumab versus interferon beta-1a in relapsing multiple sclerosis. N Engl J Med. 2017;376(3):221-34 PMID: 28002679. Available from: 10.1056/NEJMoa1601277.

47. Annibali V, Mechelli R, Romano S, Buscarinu MC, Fornasiero A, Umeton $\mathrm{R}$, et al. IFN- $\beta$ and multiple sclerosis: from etiology to therapy and back. Cytokine Growth Factor Rev. 2015;26(2):221-8. PMID: 25466632. Available from: 10.1016/j. cytogfr.2014.10.010. 